\title{
Erratum to: Effects of Global Postural Reeducation on gait kinematics in parkinsonian patients: a pilot randomized three- dimensional motion analysis study
}

\author{
Valeria Agosti ${ }^{1,2} \cdot$ Carmine Vitale $^{1,2} \cdot$ Dario Avella $^{1,2} \cdot$ Rosaria Rucco $^{2,5}$. \\ Gabriella Santangelo $^{3}$ - Pierpaolo Sorrentino ${ }^{4} \cdot$ Pasquale Varriale $^{1,2}$. \\ Giuseppe Sorrentino ${ }^{1,2}$
}

Published online: 4 February 2016

(C) Springer-Verlag Italia 2016

\section{Erratum to: Neurol Sci}

DOI 10.1007/s10072-015-2433-5

Unfortunately, the Fig. 3 was published incorrectly in the original publication. The correct figure is given below:

The online version of the original article can be found under doi:10.1007/s10072-015-2433-5.

Giuseppe Sorrentino

giuseppe.sorrentino@uniparthenope.it

Carmine Vitale

cavit69@hotmail.com

1 Department of Motor Sciences and Wellness, University of Naples Parthenope, via Medina 40, 80133 Naples, Italy

2 Institute Hermitage-Capodimonte, Naples, Italy

3 Department of Psychology, Second University of Naples, Caserta, Italy

4 Department of Neurosciences, Reproductive and Odontostomatological Sciences, University of Naples Federico II, Naples, Italy

5 Department of Sciences and Technologies, University of Naples Parthenope, Naples, Italy 

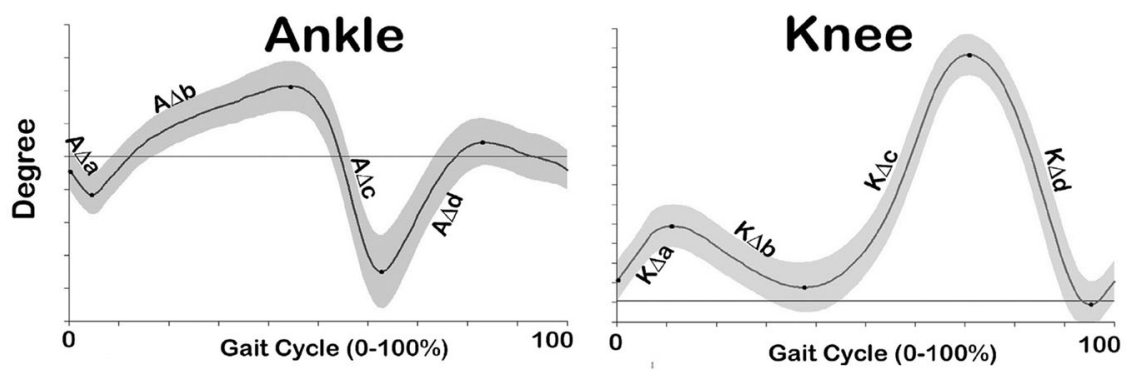

Thigh
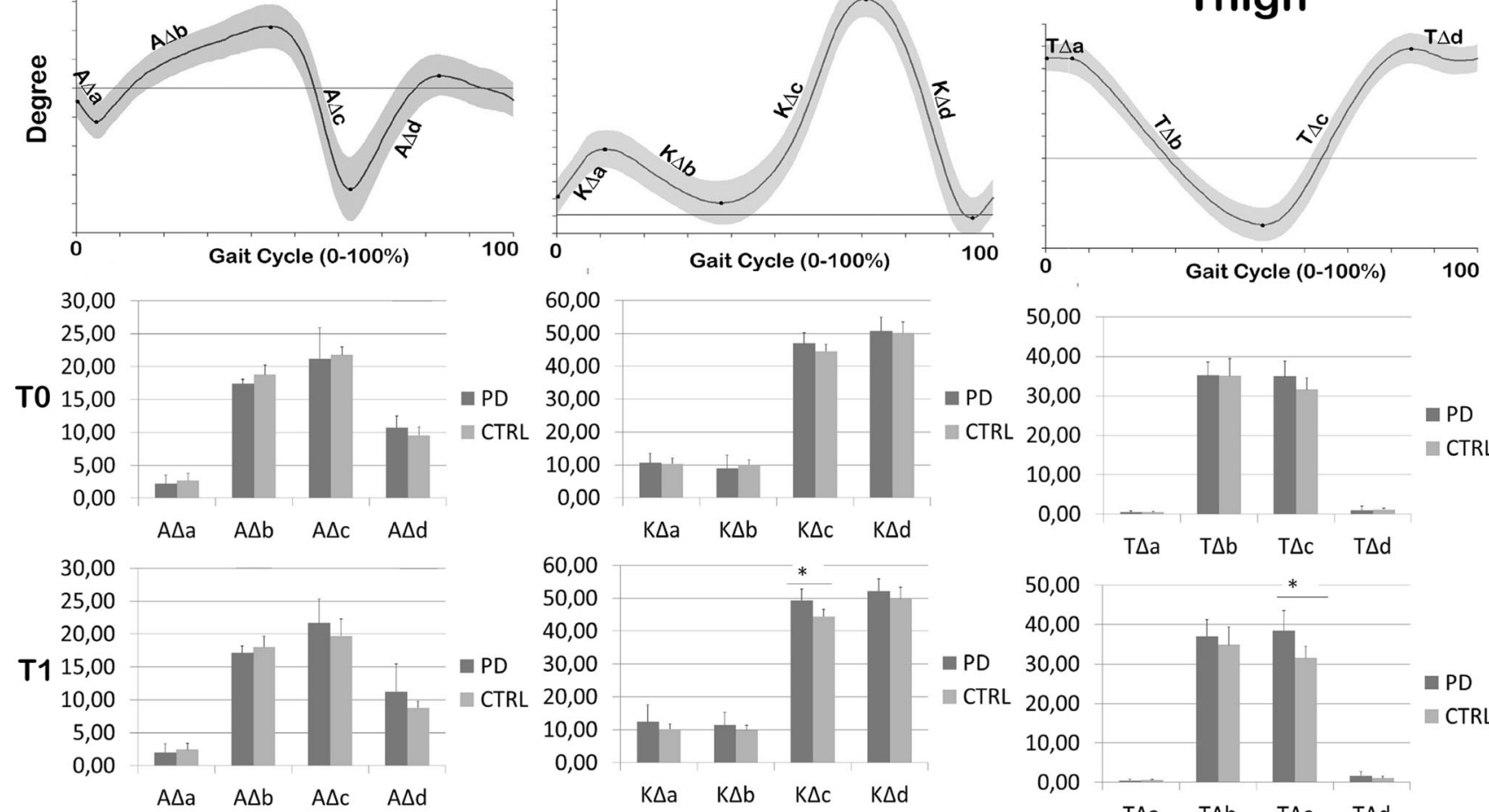

30,00

30,00

20,00
10,00

0,00

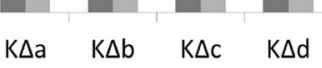

$\square \mathrm{PD}$

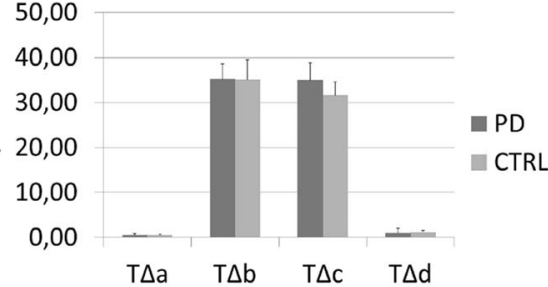

60,00

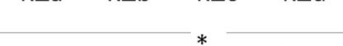

$\begin{array}{llll}\mathrm{T} \Delta \mathrm{a} & \mathrm{T} \Delta \mathrm{b} & \mathrm{T} \Delta \mathrm{c} & \mathrm{T} \Delta \mathrm{d}\end{array}$

40,00

30,00

CTRL 20,00

10,00

0,00
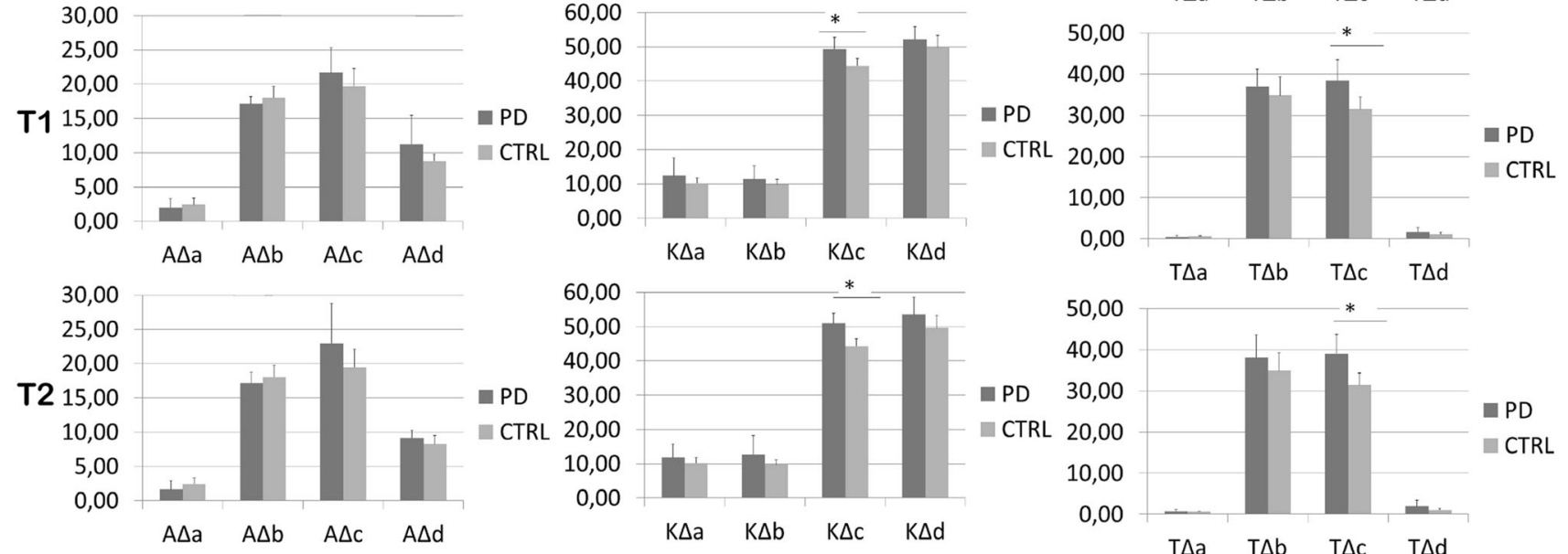

60,00

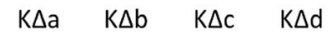

0,00

50,00

40,00
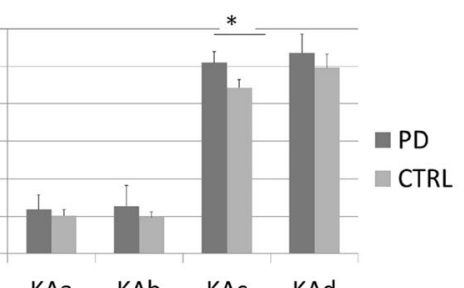

0,00

$\mathrm{K} \Delta \mathrm{a}$

$\mathrm{K} \Delta \mathrm{c} \quad \mathrm{K} \Delta \mathrm{d}$
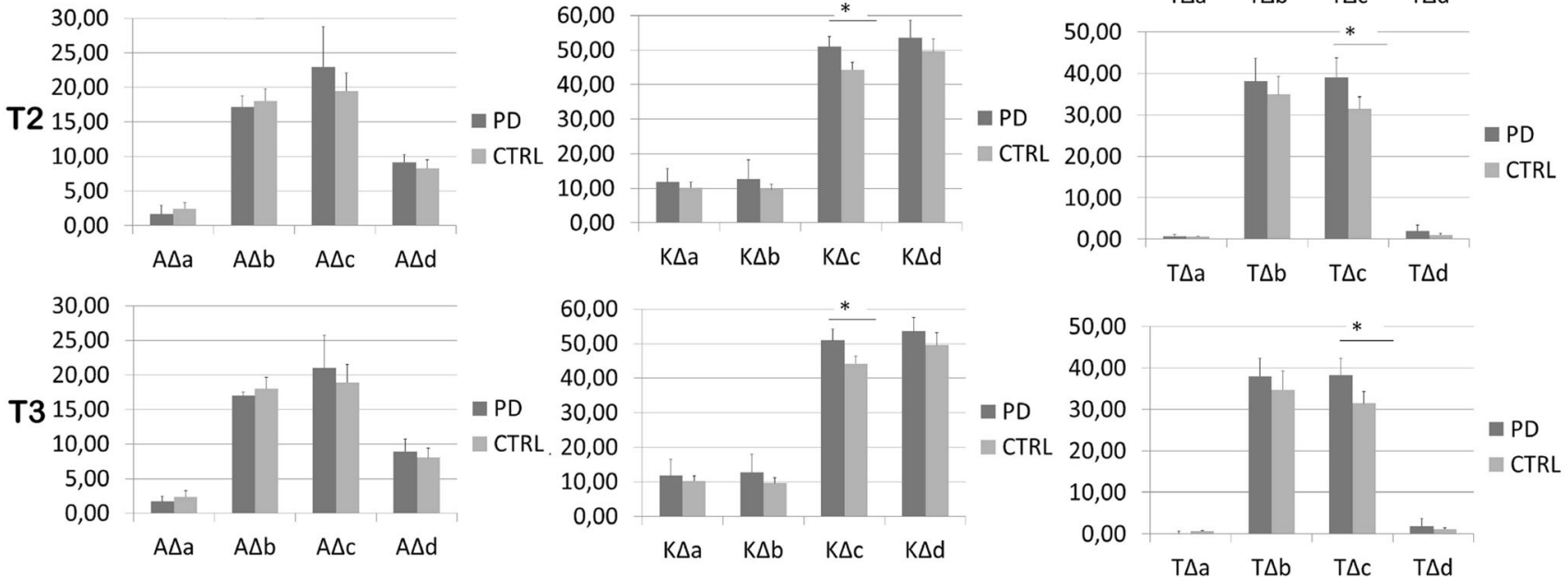

Fig. 3 The effect of 4 weeks GPR program on the RoM of the thigh $(\mathrm{T})$, knee (K), and ankle (A) joints on the sagittal plane in PD vs. control group at different times. The RoMs for each joint were normalized for the $100 \%$ of the gait cycle. $\Delta s$ value represents the

difference between two consecutive peaks in the gait cycle. Details in the text. *Statistical significance as compared to baseline evaluation (pre-test) $p<0.005$ 